\title{
Fluorescence of Size-Fractioned Humic Substance Extracted from Sediment and Its Effect on the Sorption of Phenanthrene
}

\author{
Mei-Sheu Shi ${ }^{1}$, Wei-Shiang Huang ${ }^{2}$, Liang-Fong Hsu ${ }^{3}$, Yi-Lung Yeh ${ }^{1}$ and Ting-Chien Chen ${ }^{2, *}$ \\ 1 Department of Civil Engineering, National Pingtung University of Science and Technology, Pingtung 91201, \\ Taiwan; 3001@ptfire.gov.tw (M.-S.S.); yalung@mail.npust.edu.tw (Y.-L.Y.) \\ 2 Department of Environmental Science and Engineering, National Pingtung University of Science and Technology, \\ Pingtung 91201, Taiwan; stefsun921015@gmail.com \\ 3 Department of Applied English, Tainan University of Technology, Tainan 71002, Taiwan; \\ td0011@mail.tut.edu.tw \\ * Correspondence: chen5637@mail.npust.edu.tw; Tel.: +886-8774-0333
}

Received: 12 November 2019; Accepted: 10 December 2019; Published: 13 December 2019

check for updates

\begin{abstract}
Phenanthrene (Phe) is a toxin and is ubiquitous in the environment. The sediment humic substances (HS) that bind Phe affect the fate, transport, degradation, and ecotoxicology of Phe. This study investigated Phe sorption constants on size-fractioned HS extracted from river sediment. Fractions were identified as HHS (10 kDa to $0.45 \mu \mathrm{m})$, MHS (1-10 kDa), and LHS $(<1 \mathrm{kDa})$. A fluorescence quenching (FQ) method was used to determine the Phe $\log \mathrm{K}_{\mathrm{HS}}$ on size-fractioned $\mathrm{HS}$; the values ranged from 3.97 to $4.68 \mathrm{~L} / \mathrm{kg}$-C. The sorption constant $\left(\log \mathrm{K}_{\mathrm{HS}}\right)$ is a surrogate of the binding capacity between $\mathrm{HS}$ and Phe, where a high $\log \mathrm{K}_{\mathrm{HS}}$ reduces the toxicity and degradation of Phe. The $\log \mathrm{K}_{\mathrm{HS}}$ values on HHS and MHS were significantly higher than the values on LHS $(p=0.015)$. The $\mathrm{SUVA}_{254}$ values of HHS and MHS were also significantly higher than the LHS value $(p=0.047)$, while fluorescence index (FI) and $\mathrm{S}_{275-295}$ values were significantly lower than the LHS values $(p<0.005)$. The HHS and MHS had a higher aromaticity and more terrestrial sources than LHS. The $\log \mathrm{K}_{\mathrm{HS}}$ had a significant correlation with the selected optical indicators $(p<0.002)$, which suggested that the HS-bound Phe was positively affected by high aromaticity, terrestrial sources, and HS molecular weight. The results demonstrated that optical methods successfully obtained $\log \mathrm{K}_{\mathrm{HS}}$ and the chemical properties of fractioned HS as well as the influenced factors of $\log \mathrm{K}_{\mathrm{HS}}$. Moreover, even the LHS had a capacity to bind with Phe.
\end{abstract}

Keywords: phenanthrene; sediment humic substances; size-fractioned HS; fluorescence quenching; sorption constants $\log \mathrm{K}_{\mathrm{HS}}$

\section{Introduction}

In sediment, humic substances (HS) control the sorption, fate, transport, degradation, and ecotoxicology of sediment-bound hydrophobic organic compounds (HOCs) [1-7]. HS is a heterogeneous organic mixture and is an important sediment component that binds HOCs. The extent of HOC binding on HS is related to the level of aromatic content, molecular weight, and hydrophobicity of HS and environmental conditions such as $\mathrm{pH}$ of the medium [4-10].

The chemical composition and structure of HS are particularly useful for studying the interaction between HOCs and HS and for identifying the underlying behavior mechanisms [5-7,9-13]. Studies have shown that HS structural characteristics are particularly complicated because of their natural complexity. The size, structure, and composition of HS vary greatly, depending on the origin and humification of the material [3-7]. 
In previous studies, HS samples were characterized by many methods, such as Nuclear Magnetic Resonance (NMR), element ratio, Gas Chromatography/Mass Spectrometry (GC/MS) [5,7,8], and ultraviolet and fluorescence spectra. Fluorescence and ultraviolet spectroscopy are very sensitive and useful techniques, which are often used to monitor river water, compost, landfill leaching water, dissolved organic matter (DOM), and HS extracted from soil and sediment [14-20].

Polycyclic aromatic hydrocarbon (PAH) compounds are toxic HOC substances and are ubiquitous in the environment. PAHs adsorb onto sediment, soil, and suspended particulate matter [1-3]. Moreover, PAHs bind with colloidal DOM isolated from river and seawater as well as humic substances extracted from soil and sediment [4-13,21-23]. One PAH, phenanthrene (Phe), is a moderately hydrophobic compound (the octanol-water partition coefficient, $\log \mathrm{K}_{\mathrm{OW}}=4.57$ ) that favors sorption in sediment HS $[1,23]$. However, the Phe organic carbon-normalized sorption coefficients $\left(\log \mathrm{K}_{\mathrm{OC}}\right)$ show great variation $[1-3,5,6,11,21-23]$.

Studies have observed that aquatic DOM/HS with different molecular weights exhibited varied aromaticity and hydrophobicity, and thus different binding affinities to contaminants [7,9,10,13,24-28]. The sample HS molecular weight and composition heterogeneity may provide an important contribution to binding behavior between HS and PAHs [5-7,9-13,21]. Previously, low-molecular-weight DOM/HS $(<1 \mathrm{kDa}, \mathrm{LMW})$ were assumed to have an insignificant sorption capacity on HOCs [29]. However, other studies have observed that low-molecular-weight DOM/HS had a strong sorption capacity on HOCs and heavy metals [27,29-32], even with sorption constants of LMW DOM being higher than high-molecular-weight DOM [29,30,32].

PAH compounds have a strong fluorescence intensity at a specific wavelength that was used to obtain the binding constant while PAH intensity is quenching at PAH binding to HS. Hence, a fluorescence quenching (FQ) method was used to study the sorption behavior of PAHs and HS/DOM [12,13,23,24,28,33-37], but little attention was given to sediment HS with different molecular weights, especially low-molecular-weight HS $(<1 \mathrm{kDa})$. Furthermore, sediment HS chemical properties and sorption behavior affected by the drying processes (air-drying (AD) and freeze drying (FD)) have been less studied [22].

This study investigated the binding constants of Phe sorption on size-fractioned HS extracted from river sediment. The extracted HS solution was separated into three size fractions that were identified as HHS (10 kDa to $0.45 \mu \mathrm{m})$, MHS (1-10 kDa), and LHS $(<1 \mathrm{kDa})$. The size-fractioned HS characteristics were examined by three optical indices, $\mathrm{SUVA}_{254}, \mathrm{~S}_{275-295}$, and fluorescence index (FI), which were surrogates of aromaticity, molecular weight, and terrestrial sources, respectively. Phe binding constants on size-fractioned HHS, MHS, and LHS were measured with a fluorescence-quenching method. Our studies showed that the sorption constant $\left(\log \mathrm{K}_{\mathrm{HS}}\right)$ implied a binding capacity between Phe and $\mathrm{HS}$; a high $\log \mathrm{K}_{\mathrm{HS}}$ increased the Phe binding with $\mathrm{HS}$ and reduced the toxicity and degradation of Phe [29].

\section{Research Method and Material}

\subsection{Sample Preparation}

Samples of surface sediments $(0-5 \mathrm{~cm})$ were collected with a grab sampler from WuLo Creek $\left(22^{\circ} 46^{\prime} 16.2^{\prime \prime} \mathrm{N}, 120^{\circ} 30^{\prime} 55.1^{\prime \prime} \mathrm{E}\right)$, Taiwan. The creek receives a large amount of wastewater discharged from livestock; hence, the sediment is rich in organic matter. One of collected sample was air-dried for one year and designated as the AD sample. Another sample, designated FD, was kept in a freezer for one year, then freeze-dried. The AD and FD samples were ground and passed through a $2.0-\mathrm{mm}$ sieve. The sediment total organic carbon (TOC) content was analyzed using a Multi $3000 \mathrm{TOC} / \mathrm{TN}$ (total organic carbon/total nitrogen) analyzer (Analytik Jena, Thuringia, Germany). The sediment humic substances (HS) were extracted using $0.1 \mathrm{M} \mathrm{NaOH}$ at $w / v=1 / 20$ ratio. 


\subsection{HS Size Fraction Separation}

The extracted bulk HS (BHS) solution was adjusted to $\mathrm{pH} 7$ and passed through a $0.45-\mu \mathrm{m}$ filter. Then, the neutral BHS solutions were separated into three size fractions: $10 \mathrm{kDa}<\mathrm{HHS}<0.45 \mu \mathrm{m}$, $1 \mathrm{kDa}<\mathrm{MHS}<10 \mathrm{kDa}$, and LHS $<1 \mathrm{kDa}$, using cross-flow ultrafiltration equipment with a nominal weight molecular cutoff ceramic membrane cartridge (Filtanium, France, cut-off pore sizes 10 and $1 \mathrm{kDa}$, sequent, membrane area of $320 \mathrm{~cm}^{2}$ ), operating at a feed flow rate of $1.7-2.0 \mathrm{~L} / \mathrm{min}$. The penetration flow rates were 12 and $25 \mathrm{~mL} / \mathrm{min}$ for the 10 and $1 \mathrm{kDa}$ membranes, respectively. The working pressure was $5 \mathrm{~kg} / \mathrm{cm}^{2}$. The BHS and three size-fractioned HS were measured with UV/Vis and fluorescence spectroscopy. Concentrations of dissolved organic carbon (DOC) for the bulk and size-fractioned HS samples were quantified by a TOC analyzer (TOC-L, Shimadzu, Tokyo, Japan).

\subsection{UV/Vis Measurements}

HS solution absorbance was measured with a UV/Vis spectrophotometer (U-2900, Hitachi, Tokyo, Japan), on a scanning wavelength of 200-800 nm. Background was corrected in accordance with the method reported by Helms et al. [17]. SUVA $254(\mathrm{~L} / \mathrm{m} / \mathrm{mg}-\mathrm{C})=\left(\mathrm{UV}_{254} /[\mathrm{HS}]\right) \times 100, \mathrm{UV}_{254}\left(\mathrm{~cm}^{-1}\right)$ was used as the UV/Vis absorbance indicator at $254 \mathrm{~nm}$, and [HS] was the DOC concentration (mg-C/L) of the HS solution [15]. UV/Vis indicator $\mathrm{S}_{275-295}$ was the slope of absorbance at a wavelength interval of 275-295 nm [17].

\subsection{Fluorescence Spectroscopy}

A three-dimensional fluorescence excitation/emission matrix (EEM) was recorded by fluorescence spectrophotometer (F-7000, Hitachi, Tokyo, Japan) at $5 \mathrm{mg}-\mathrm{C} / \mathrm{L}$. Before measurement, the HS solution was adjusted to $\mathrm{pH} 7$ with $0.3 \mathrm{~N} \mathrm{H}_{2} \mathrm{SO}_{4}$. Fluorescent scanning conditions were as follows: excitation wavelength $200-450 \mathrm{~nm}$ at 5-nm increments, emission wavelength $250-550 \mathrm{~nm}$ at 2-nm increments, and scan rate $2400 \mathrm{~nm} / \mathrm{min}$. The spectra were obtained by subtracting an ultrapure water blank spectrum, recorded in the same conditions, to eliminate the Raman scatter peaks. The fluorescence index (FI) is the fluorescence intensity ratio of emission wavelengths at 450 and $500 \mathrm{~nm}$ with the excitation wavelength at $370 \mathrm{~nm}$ [20].

\subsection{Fluorescence Quenching}

Seven different HS concentrations were prepared (1-20 mg-C/L). Next, $1 \mathrm{mg} / \mathrm{L}$ Phe standard solution was added to each HS solution. This was followed by reciprocal shaking for $24 \mathrm{~h}$ (150 rpm), using $0.3 \mathrm{~N} \mathrm{H}_{2} \mathrm{SO}_{4}$ solution adjusted to $\mathrm{pH} 7$. The solution was measured with fluorescence spectroscopy (Hitachi, F-7000). The fluorescence intensity at $\mathrm{Ex} / \mathrm{Em}=250 / 349 \mathrm{~nm}$ of the HS solutions was detected. Since the UV/Vis absorbance at $254 \mathrm{~nm}$ was less than $0.2 \mathrm{~cm}^{-1}$, the inner filter effect was not corrected.

HS and the PAH sorption coefficients were calculated using the Stern-Volmer equation as Equation (1) [35]:

$$
\frac{F_{0}}{F}=1+\mathrm{K}_{\mathrm{HS}}[\mathrm{HS}],
$$

where $F$ and $F_{0}$ are the fluorescence intensities of the standard Phe solution with and without HS solution present, respectively. [HS] is the DOC concentration of $\mathrm{HS}(\mathrm{mg}-\mathrm{C} / \mathrm{L})$ and $\mathrm{K}_{\mathrm{HS}}$ is the sorption coefficient ( $\mathrm{L} / \mathrm{mg}-\mathrm{C})$. It should be noted that Equation (1) assumes the Phe sorption on the HS solution had static quenching [35]. The $\mathrm{K}_{\mathrm{HS}}$ was determined through the linear regression of the $F_{0} / F$ values with the DOC concentration of HS. The linear significance was dependent on whether the slope and intercept had the necessary significance $(p<0.05)$ to determine the suitability of the Stern-Volmer equation. The linear slope was the $\mathrm{K}_{\mathrm{HS}}(\mathrm{L} / \mathrm{mg}-\mathrm{C})$, which was taken from logarithm to $\log \mathrm{K}_{\mathrm{HS}}(\mathrm{L} / \mathrm{kg}-\mathrm{C})$. 


\subsection{Statistical Analysis and Calculation of Fluorescence Data}

In this study, using the R software (V 2.13.2) (R Core Team, Vienna, Austria) to calculate fluorescence and UV/Vis indicators, the R script developed by Lapworth and Kinniburgh [38] was followed. Linear regression and the difference test used the S-PLUS software (V 6.2) (Insightful Corporation, Seattle, WA, USA). The indicator difference test for the three size-fractioned HS solutions used the ANOVA test methods, and two-group data sets used the $t$-test method at significance levels of $p<0.05$.

\section{Results and Discussion}

\subsection{DOC Concentration and Carbon Mass Fraction of Size-Fractioned HS}

The experimental sediments were both air-dried (AD) and freeze-dried (FD); the properties of the $\mathrm{AD}$ and FD samples are listed in Table 1. The $\mathrm{pH}$ values of the AD and FD samples were from 7.05 to 7.28. The AD and FD levels of organic matter (OM) and total organic carbon (TOC) were $5.55-7.90 \%$ and $1.71-3.95 \%$, respectively. The OM and TOC concentrations were similar to the concentration in river sediment $[3,27]$. The OM and TOC FD concentrations were greater than the AD concentration but only slightly ( $p$-values of 0.66 and 0.73 , respectively). The AD-treated samples had slightly lower $\mathrm{OM}$ and TOC concentrations and $\mathrm{pH}$, which may be attributed to the labile fraction of organic matter hydrolysis and biodegradation during the one-year drying procedure. The AD treatment produced higher hydrolysis and biodegradation than the FD treatment. Hence, AD samples generated more organic acid at a low $\mathrm{pH}$ value $[39,40]$.

Table 1. Sediment chemical properties for both air-dried (AD) and freeze-dried (FD) samples.

\begin{tabular}{cccc}
\hline Samples & $\mathbf{p H}$ & $\mathbf{O M} \mathbf{( \% )}$ & TOC (\%) \\
\hline AD & $7.14 \pm 0.12$ & $6.60 \pm 1.03$ & $2.51 \pm 0.69$ \\
FD & $7.22 \pm 0.03$ & $7.06 \pm 1.36$ & $2.71 \pm 0.70$ \\
\hline \multicolumn{4}{c}{ Organic matter (OM); total organic carbon (TOC). }
\end{tabular}

The DOC concentrations of BHS and the three size-fractioned HS are listed in Table 2. The BHS DOC concentrations were $297 \pm 28 \mathrm{mg}-\mathrm{C} / \mathrm{L}(5.94 \pm 0.56 \mathrm{~g} / \mathrm{kg}$ based on sediment mass $)$ and $320 \pm 48$ $\mathrm{mg}-\mathrm{C} / \mathrm{L}(6.40 \pm 0.96 \mathrm{~g} / \mathrm{kg}$ based on sediment mass) for AD and FD samples, respectively; there was an insignificant difference between the two procedures $(p=0.51)$. The alkaline-extracted HS DOC concentrations in our study were higher than the water-extracted organic carbon from lake sediment reported by $\mathrm{Xu}$ et al. [32]. In each size-fractioned HS sample, the DOC concentration was insignificantly different between the AD and FD samples ( $p$-values of 0.16-0.93).

Table 2. Measured dissolved organic carbon (DOC) concentrations of bulk humic substances (HS) and three size-fractioned HS for both AD and FD samples.

\begin{tabular}{ccccc}
\hline Samples & BHS mg/L & HHS mg/L & MHS mg/L & LHS mg/L \\
\hline AD & $276-329$ & $1451-1833$ & $638-752$ & $59-78$ \\
FD & $279-370$ & $1108-2220$ & $728-946$ & $52-71$ \\
\hline
\end{tabular}

Molecular weight of humic substances: BHS $(<0.45 \mu \mathrm{m})$, HHS (10 kDa-0.45 $\mu \mathrm{m})$, MHS (1 kDa-10 kDa), and LHS $(<1 \mathrm{kDa})$.

Since the HS DOC concentrations of the two drying procedures were insignificantly different than the DOC concentrations of each size-fractioned HS, they were considered as pool samples. The order of measured DOC concentrations was $1660 \pm 373 \mathrm{mg}-\mathrm{C} / \mathrm{L}$ (HHS) $>754 \pm 110 \mathrm{mg}-\mathrm{C} / \mathrm{L}$ (MHS) $>66.8 \pm 9.3$ $\mathrm{mg}-\mathrm{C} / \mathrm{L}$ (LHS) $(p<0.001)$. The volume fractions for the HS separation were 1.0, $0.1,0.09$, and 0.81 for BHS, HHS, MHS, and LHS, respectively. The carbon mass balances were $95.3 \% \pm 8.3 \%$ (AD) and $92.4 \% \pm 15.0 \%$ (FD), which is within a reasonable range ( $80-120 \%$ for DOM/HS separated into different sized fractions) $[27,32,41-43]$. 
The carbon mass fractions were $57.1 \% \pm 6.5 \%, 23.8 \% \pm 4.4 \%$, and $19.1 \% \pm 4.1 \%$ for HHS, MHS, and LHS, respectively. The carbon mass of the high-molecular-weight fraction (HMW, $>1 \mathrm{kDa}$ ) averaged $81 \%$, which was greater than the carbon mass fraction of the water-extracted organic matter from lake sediment (52-58\%) [32]. The HMW carbon mass fraction was much higher than that in river water, lake water, seawater, and estuary, which ranged from $23 \%$ to $66 \%$ in the literature $[13,41,44,45]$. The OM sediment continuously suffered hydrolysis and biodegradation. The low-molecular-weight labile OM fraction was readily decomposed, which left the OM high-molecular-weight carbon fraction in the sediment as reported by previous studies $[39,40,46]$.

\subsection{Optical Indicators}

The HS and DOM optical indices provide useful information [14-19]. In this study, two UV/Vis and one fluorescence indicator were adopted to analyze the chemical properties of the size-fractioned HS: specific ultraviolet absorbance at wavelength at $254 \mathrm{~nm}\left(\mathrm{SUVA}_{254}\right)$ [15], spectroscopy slope between 275 and $295 \mathrm{~nm}\left(\mathrm{~S}_{275-295}\right)$ [17], and FI [16,20].

The UV/Vis indicators of the size-fractioned HS in both AD and FD samples are listed in Table 3. In each size-fractioned HS, the indicator values were insignificantly different between the AD and FD samples (except the $S_{275-295}$ of LHS). The AD sample $S_{275-295}$ values were lower than the FD, which suggested that the AD sample had a higher molecular weight than the FD in the LHS samples.

Table 3. Optical indicators of three size-fractioned HS for both AD and FD samples.

\begin{tabular}{cccc}
\hline Samples (MW) & SUVA $254(\mathbf{L} / \mathbf{m g}-\mathrm{C} / \mathbf{m})$ & S $_{275-295}$ & FI \\
\hline AD_HHS (10 kDa to 0.45 $\mu \mathrm{m})$ & $2.26 \pm 0.62^{\mathrm{a}}$ & $0.0121 \pm 0.0006^{\mathrm{a}}$ & $1.47 \pm 0.05^{\mathrm{a}}$ \\
FD_HHS $(10 \mathrm{kDa}$ to $0.45 \mu \mathrm{m})$ & $3.11 \pm 0.54^{\mathrm{a}}$ & $0.0120 \pm 0.0002^{\mathrm{a}}$ & $1.47 \pm 0.01^{\mathrm{a}}$ \\
AD_MHS $(1-10 \mathrm{kDa})$ & $2.95 \pm 0.34^{\mathrm{a}}$ & $0.0117 \pm 0.0006^{\mathrm{a}}$ & $1.46 \pm 0.01^{\mathrm{a}}$ \\
FD_MHS $(1-10 \mathrm{kDa})$ & $2.02 \pm 0.66^{\mathrm{a}}$ & $0.0133 \pm 0.0016^{\mathrm{a}}$ & $1.49 \pm 0.02^{\mathrm{a}}$ \\
AD_LHS $(<1 \mathrm{kDa})$ & $1.75 \pm 0.38^{\mathrm{b}}$ & $0.0153 \pm 0.0006^{*} \mathrm{~b}$ & $1.76 \pm 0.01^{\mathrm{b}}$ \\
FD_LHS $(<1 \mathrm{kDa})$ & $1.75 \pm 0.14^{\mathrm{b}}$ & $0.0177 \pm 0.0006^{\mathrm{b}}$ & $1.81 \pm 0.04^{\mathrm{b}}$ \\
\hline
\end{tabular}

MW: molecular weight; ${ }^{*}$ indicates AD and FD were significantly different $(p<0.05){ }^{\text {a,b }}$ indicate that the sized fractions had significant difference $(p<0.005)$.

In comparison, the indicator values of each of the $\mathrm{AD}$ and FD size-fractioned samples were calculated as a pool sample. SUVA 254 is a surrogate for the abundance of aromatic group in HS. A large $\mathrm{SUVA}_{254}$ value indicates a high aromatic group content in HS [15,25]. The average SUVA 254 values were $2.69 \pm 0.69$ and $2.48 \pm 0.69 \mathrm{~L} / \mathrm{mg}-\mathrm{C} / \mathrm{m}$ for HHS and MHS, respectively. They were significantly greater than the average LHS value of $1.75 \pm 0.26 \mathrm{~L} / \mathrm{mg}-\mathrm{C} / \mathrm{m}(p=0.047)$. The $\mathrm{SUVA}_{254}$ values of the three size-fractioned HS samples were $<3$, which suggested that the composition of the studied HS samples contained predominantly hydrophilic substances [14].

The $\mathrm{S}_{275-295}$ indicator is a surrogate for the average molecular weight of HS. The indicator value was inverse-correlated with the DOM molecular weight [17-19]. The $S_{275-295}$ values were $0.0120 \pm 0.0004$ and $0.0125 \pm 0.0014$ for HHS and MHS, respectively. They were significantly lower than the $\mathrm{S}_{275-295}$ value of LHS $-0.0165 \pm 0.0014(p=0.005)$. The $\mathrm{SUVA}_{254}$ and $\mathrm{S}_{275-295}$ indicator values had a strong negative correlation $(r=-0.73, p<0.001)$.

The FI is an indicator used to discriminate the DOM sources (e.g., microbial or terrestrial) $[16,20]$. The FI values were $1.47 \pm 0.03$ and $1.47 \pm 0.02$ for HHS and MHS, respectively. They were significantly lower than the FI value of $\mathrm{LH}-1.78 \pm 0.04(p=0.005)$. The indicator results suggested that HHS and MHS had more contribution from terrestrial sources than LHS. The UV/Vis and fluorescence indicators showed that the three size-fractioned HS samples primarily contained hydrophilic substances of aquatic media and microbial origin, as well as a low degree of humification [14,16,18-20].

The HS indicators were comparable to water- and alkaline-extracted organic matter from river sediment, such as $\mathrm{SUVA}_{254}$ values that ranged from 0.2 to $3.7 \mathrm{~L} / \mathrm{mg}-\mathrm{C} / \mathrm{m}$, as reported by previous studies [5-7,27], The reported FI values ranged from 1.3 to 2.3 , as reported by previous 
studies $[6,7,16,27,32]$. The $\mathrm{S}_{275-295}$ values were higher than the alkaline-extracted organic matter, which ranged from 0.0074 to 0.0095 , as reported by Hur et al. [5]. The $S_{275-295}$ values were lower than the water-extracted organic matter, which ranged from 0.017 to 0.018 , as reported by $\mathrm{Xu}$ et al. [32].

There are few reported optical indicators for size-fractioned HS. Xu et al. [32] discussed the optical indicators of high-molecular-weight organic matter ( $1 \mathrm{kDa}$ to $0.45 \mu \mathrm{m}, \mathrm{HMW})$ and low-molecular-weight organic matter $(<1 \mathrm{kDa}, \mathrm{LMW})$ extracted from river sediment. The HMW SUVA 254 values ranged from $2.05 \pm 0.03$ to $5.12 \pm 0.07 \mathrm{~L} / \mathrm{mg}-\mathrm{C} / \mathrm{m}$ and the those of the LMW ranged from $8.25 \pm 0.14$ to $14.60 \pm 0.25 \mathrm{~L} / \mathrm{mg}-\mathrm{C} / \mathrm{m}$. The SUVA 254 values were higher than our study and the HMW values were higher than LMW, which is the reverse of our study.

In the $\mathrm{Xu}$ et al. [32] study, the HMW $\mathrm{S}_{275-295}$ values were $0.009 \pm 0.001$ and $0.0118 \pm 0.001$ and the LMW values were $0.028 \pm 0.002$ and $0.0188 \pm 0.001$. The $S_{275-295}$ values were comparable to our results and HMW had low $S_{275-295}$ values. The HMW FI values were $1.25 \pm 0.02$ and $1.18 \pm 0.02$ and the LMW FI values were $1.52 \pm 0.03$ and $1.34 \pm 0.02$. The FI values were lower than in our study but had a similar trend; the HMW had lower FI values than the LMW. In our study, the HMW HS had more aromaticity and terrestrial sources than the LMW. However, the water-extracted organic matter as reported in Xu et al. [32] showed that the HMW had low aromaticity and more terrestrial sources. The HS sources, environmental condition, and HS extraction method affected the HS indicator values.

\subsection{Sorption Constants between HS and Phe}

The Phe sorption constants on the size-fractioned HS were measured with the FQ method. The FQ method has been previously used to test sorption constants between several PAHs onto HS $[12,13,23,24,28,33-37]$. Figure $1 \mathrm{a}, \mathrm{b}$ shows the linear regression of fluorescence intensity $F_{0} / F$ ratios of Phe with HHS, MHS, and LHS concentrations fitted with the Stern-Volmer equation for both AD and FD samples. The $F_{0} / F$ ratios of Phe increased linearly and followed the increasing HS concentrations, which indicated the intensity $(\mathrm{F})$ decreased and followed the extent of interaction between Phe and HS. This was attributed to the sorption between Phe and HS, which decreased the fluorescence intensity of Phe.

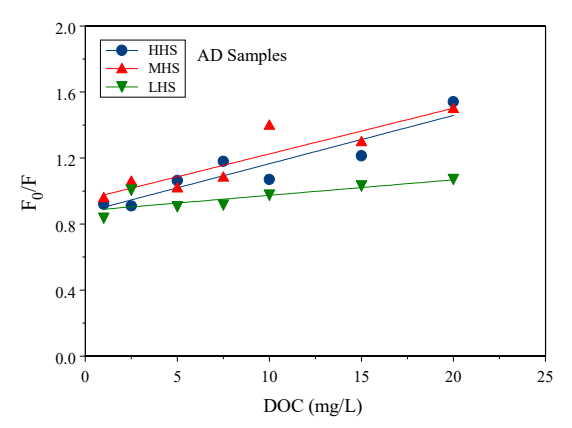

(a)

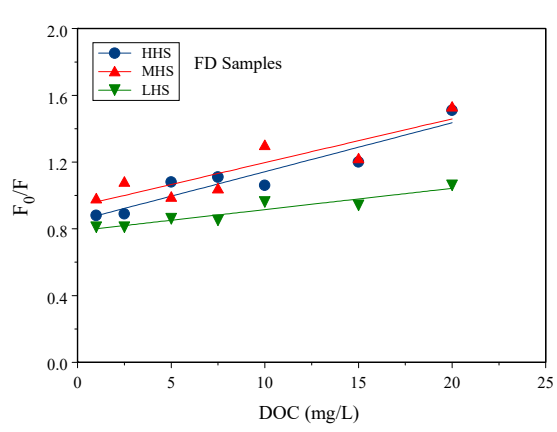

(b)

Figure 1. $F_{0} / F$ ratios with DOC concentration and linear regression curves for (a) AD sample and (b) FD sample.

Three size fractions and two drying methods were conducted. All tests were run in triplicate for a total of 18 tests. The slopes of the linear regression were the sorption constant $\mathrm{K}_{\mathrm{HS}}$ values (L/mg-C), which were transferred to $\log \mathrm{K}_{\mathrm{HS}}(\mathrm{L} / \mathrm{kg}-\mathrm{C})$. In total, 16 out of $18 \mathrm{FQ}$ tests had a significant linear relationship. In each HS size fraction, the validated FQ tests were 6, 5, and 5 samples for HHS, MHS, and LHS, respectively. The average and one standard deviation of log $\mathrm{K}_{\mathrm{HS}}$ for each size-fractioned HS are listed in Table 4. The average intercepts of regression ranged from 0.79 to 0.95 and $r^{2}$ ranged from 0.62 to 0.90 for the three size-fractioned HS. The $\log \mathrm{K}_{\mathrm{HS}}$ values of Phe sorption on the three size-fractioned HS were 3.97-4.68 L/kg-C. Several studies tested HS extracted from soils and sediments. The organic carbon normalized sorption constants $\log \mathrm{K}_{\mathrm{HS}}$ of Phe sorption on HS ranged 
from 3.76 to $6.13[1-3,5,6,21,22,34,36,37]$. These results are comparable to the sorption constants in this study.

Table 4. The sorption constants (log $\mathrm{K}_{\mathrm{HS}}$ ) of phenanthrene (Phe) with three size-fractioned HS for both $\mathrm{AD}$ and FD samples.

\begin{tabular}{cccc}
\hline Samples & HHS & MHS & LHS \\
\hline AD & $4.41 \pm 0.29(3) *$ & $4.39 \pm 0.17(3)$ & $4.09 \pm 0.10(3)$ \\
FD & $4.44 \pm 0.17(3)$ & $4.44 \pm 0.00(2)$ & $3.97 \pm 0.01(2)$ \\
\hline \multicolumn{4}{c}{ The sample number is in parentheses. }
\end{tabular}

In each size-fractioned HS, the $\log \mathrm{K}_{\mathrm{HS}}$ values were not significantly different between the AD and FD samples $(p=0.17-0.87)$. However, Phe had higher $\log \mathrm{K}_{\mathrm{HS}}$ sorption values onto HHS $(4.43 \pm 0.21)$ and MHS (4.41 \pm 0.21$)$ than sorption onto LHS $(4.04 \pm 0.09)(p=0.015)$. Several studies $[7,12,13,22,24]$ have reported that the HOCs had a higher sorption capacity onto higher molecular weight DOM because it had a higher aromatic content and higher extent of humification. Although, LHS had a lower $\log \mathrm{K}_{\mathrm{HS}}$ than HHS and MHS. It was noteworthy that generally, LMW ( $\left.<1 \mathrm{kDa}\right) \mathrm{HS}$ was considered without sorption capacity on HOCs. A few studies have observed that LMW HS/DOM had sorption on HOCs and heavy metal capacity [28-33] even higher than HMW [29,30,32].

\subsection{Correlation of $\log K_{H S}$ with Indicators}

The total $\log \mathrm{K}_{\mathrm{HS}}$ value was $4.30 \pm 0.23$ and the $\log \mathrm{K}_{\mathrm{OW}}$ of Phe was 4.57 [1,23]. The value of $\log \mathrm{K}_{\mathrm{HS}}$ was close to octanol-water partition coefficient $\left(\log \mathrm{K}_{\mathrm{OW}}\right)$ values, which suggested that hydrophobicity was an important factor that impacted the sorption behavior of Phe. The HOC $\log \mathrm{K}_{\mathrm{OW}}$ and $\log \mathrm{K}_{\mathrm{OC}}$ have been observed to have a positive relationship as reported by previous studies [47-50]. However, the independent relationship also has been observed in several studies of HOC sorption onto HS [51,52]. This suggests that the simple partitioning of PAH hydrophobicity would not accurately describe the sorption of HOCs to HS, where the chemical composition and structure as well as the HS molecular weight can be the important factors that influence the sorption behavior (as reported by previous studies [5,52]).

The correlation between $\log \mathrm{K}_{\mathrm{HS}}$ and the indicators may reflect the important factors that impact the extent of interaction between HS and Phe. Figure 2a-c shows the linear relationships of the Phe log $\mathrm{K}_{\mathrm{HS}}$ with optical indices ( $\mathrm{SUVA}_{254}, \mathrm{~S}_{275-295}$ and FI). SUVA 254 had an intermediate positive correlation with the Phe $\log \mathrm{K}_{\mathrm{HS}}\left(r^{2}=0.50, p=0.002\right)$ (Figure 2a). Both $\mathrm{S}_{275-295}$ and FI values had a significantly negative correlation with $\log \mathrm{K}_{\mathrm{HS}}\left(r^{2}=0.76, r^{2}=0.67\right.$, for $\mathrm{S}_{275-295}$ and FI, respectively, $\left.p<0.001\right)$. Low $S_{275-295}$ value and FI values indicated high molecular weight and greater contribution of terrestrial sources in HS (Figure 2b,c).

More aromatic functional groups, terrestrial sources, and high molecular weight in HS had a positive effect on Phe sorption onto HS. Previous studies have shown that aromaticity, terrestrial sources, and molecular weight had a positive correlation with sorption constants of HOCs onto HS and DOM $[5-7,10,11,13,34]$. Generally, terrestrial sources had more aromatics and high-molecular-weight HS had more intramolecular charge transfer capability, which increased the sorption capacity of HS-Phe $[5,7,10,11]$. 


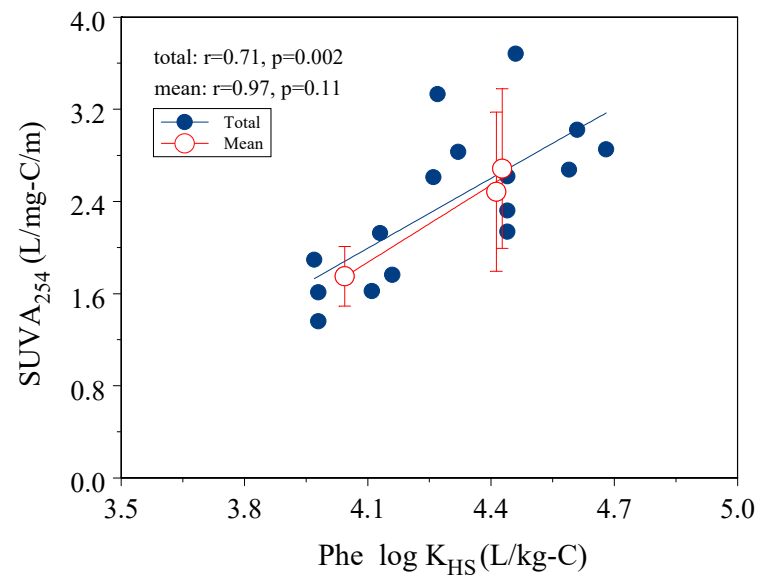

(a)

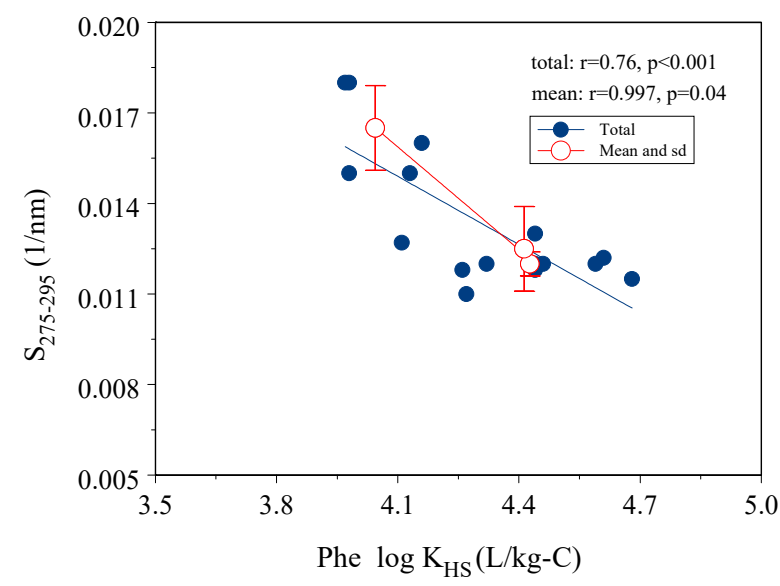

(b)

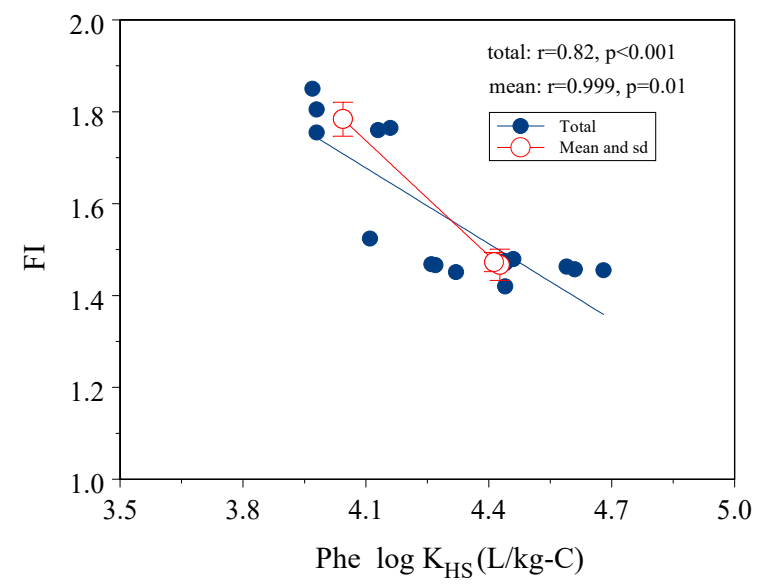

(c)

Figure 2. Correlation of Phe $\log \mathrm{K}_{\mathrm{HS}}$ with three optical indicators, (a) $\mathrm{SUVA}_{254}$; (b) $\mathrm{S}_{275-295}$; (c) FI. 


\section{Conclusions}

DOC concentrations and optical indicators, for both total and sized HS, were insignificantly different for AD or FD samples. Furthermore, the binding constants were insignificantly different between the AD and FD samples. However, HHS and MHS had higher binding constants, log $\mathrm{K}_{\mathrm{HS}}$, than LHS; the HHS and MHS had higher aromaticity, terrestrial sources, and molecular weight than LHS. The high binding capacity implied that HS-bound Phe had low toxicity to microorganisms but a long resistance in the environment. The results demonstrated that optical methods successfully obtained $\log \mathrm{K}_{\mathrm{HS}}$ and chemical properties of fractioned HS as well as the influenced factors of $\log \mathrm{K}_{\mathrm{HS}}$. Moreover, even the LHS $(<1 \mathrm{kDa})$ had significant binding capacity with Phe.

Author Contributions: Methodology: M.-S.S., W.-S.H., and T.-C.C.; Investigation and analysis: M.-S.S., and W.-S.H.; Writing—original draft preparation, review, and editing: L.-F.H., Y.-L.Y., T.-C.C.

Funding: The authors would like to thank the National Science Council of the Republic of China, Taiwan for funding this research under Contract No. NSC 101-2621-M-020-007.

Conflicts of Interest: The authors declare no conflict of interest.

\section{References}

1. Wang, X.-C.; Zhang, Y.-X.; Chen, R.F. Distribution and partitioning of polycyclic aromatic hydrocarbons (PAHs) in different size fractions in sediments from Boston Harbor, United States. Mar. Pollut. Bull. 2001, 42, 1139-1149. [CrossRef]

2. Shang, J.; Chen, J.; Shen, Z.; Wang, Y.; Ruan, A. Effects of varying estuarine conditions on the sorption of phenanthrene to sediment particles of Yangtze Estuary. Mar. Pollut. Bull. 2013, 76, 139-145. [CrossRef] [PubMed]

3. Sun, K.; Jin, J.; Gao, B.; Zhang, Z.; Wang, Z.; Pan, Z.; Xu, D.; Zhao, Y. Sorption of $17 \alpha$-ethinyl estradiol, bisphenol A and phenanthrene to different size fractions of soil and sediment. Chemosphere 2012, 88, 577-583. [CrossRef] [PubMed]

4. Sun, W.; Ni, J.; Xu, N.; Sun, L. Fluorescence of sediment humic substance and its effect on the sorption of selected endocrine disruptors. Chemosphere 2007, 66, 700-707. [CrossRef]

5. Hur, J.; Lee, D.-H.; Shin, H.-S. Comparison of the structural, spectroscopic and phenanthrene binding characteristics of humic acids from soils and lake sediments. Org. Geochem. 2009, 40, 1091-1099. [CrossRef]

6. Hur, J.; Lee, B.-M.; Shin, K.-H. Spectroscopic characterization of dissolved organic matter isolates from sediments and the association with phenanthrene binding affinity. Chemosphere 2014, 111, 450-457. [CrossRef]

7. Hur, J.; Kim, G. Comparison of the heterogeneity within bulk sediment humic substances from a stream and reservoir via selected operational descriptors. Chemosphere 2009, 75, 483-490. [CrossRef]

8. Vitale, C.M.; Di Guardo, A. A review of the predictive models estimating association of neutral and ionizable organic chemicals with dissolved organic carbon. Sci. Total Environ. 2019, 666, 1022-1032. [CrossRef]

9. Hur, J.; Schlautman, M.A. Influence of humic substance adsorptive fractionation on pyrene partitioning to dissolved and mineral-associated humic substances. Environ. Sci. Technol. 2004, 38, 5871-5877. [CrossRef]

10. Lee, Y.K.; Lee, M.-H.; Hur, J. A new molecular weight (MW) descriptor of dissolved organic matter to represent the MW-dependent distribution of aromatic condensation: Insights from biodegradation and pyrene binding experiments. Sci. Total Environ. 2019, 660, 169-176. [CrossRef]

11. Hur, J.; Park, S.-W.; Kim, M.C.; Kim, H.S. Enhanced binding of hydrophobic organic contaminants by microwave-assisted humification of soil organic matter. Chemosphere 2013, 93, 2704-2710. [CrossRef] [PubMed]

12. Gustafsson, Ö.; Nilsson, N.; Bucheli, T.D. Dynamic colloid- water partitioning of pyrene through a coastal Baltic spring bloom. Environ. Sci. Technol. 2001, 35, 4001-4006. [CrossRef] [PubMed]

13. Holbrook, R.D.; Love, N.G.; Novak, J.T. Investigation of sorption behavior between pyrene and colloidal organic carbon from activated sludge processes. Environ. Sci. Technol. 2004, 38, 4987-4994. [CrossRef] [PubMed] 
14. Matilainen, A.; Gjessing, E.T.; Lahtinen, T.; Hed, L.; Bhatnagar, A.; Sillanpää, M. An overview of the methods used in the characterisation of natural organic matter (NOM) in relation to drinking water treatment. Chemosphere 2011, 83, 1431-1442. [CrossRef] [PubMed]

15. Weishaar, J.L.; Aiken, G.R.; Bergamaschi, B.A.; Fram, M.S.; Fujii, R.; Mopper, K. Evaluation of specific ultraviolet absorbance as an indicator of the chemical composition and reactivity of dissolved organic carbon. Environ. Sci. Technol. 2003, 37, 4702-4708. [CrossRef] [PubMed]

16. Birdwell, J.E.; Engel, A.S. Characterization of dissolved organic matter in cave and spring waters using UV-Vis absorbance and fluorescence spectroscopy. Org. Geochem. 2010, 41, 270-280. [CrossRef]

17. Helms, J.R.; Stubbins, A.; Ritchie, J.D.; Minor, E.C.; Kieber, D.J.; Mopper, K. Absorption spectral slopes and slope ratios as indicators of molecular weight, source, and photobleaching of chromophoric dissolved organic matter. Limnol. Oceanogr. 2008, 53, 955-969. [CrossRef]

18. Li, P.; Hur, J. Utilization of UV-Vis spectroscopy and related data analyses for dissolved organic matter (DOM) studies: A review. Crit. Rev. Environ. Sci. Technol. 2017, 47, 131-154. [CrossRef]

19. Hansen, A.M.; Kraus, T.E.; Pellerin, B.A.; Fleck, J.A.; Downing, B.D.; Bergamaschi, B.A. Optical properties of dissolved organic matter (DOM): Effects of biological and photolytic degradation. Limnol. Oceanogr. 2016, 61, 1015-1032. [CrossRef]

20. McKnight, D.M.; Boyer, E.W.; Westerhoff, P.K.; Doran, P.T.; Kulbe, T.; Andersen, D.T. Spectrofluorometric characterization of dissolved organic matter for indication of precursor organic material and aromaticity. Limnol. Oceanogr. 2001, 46, 38-48. [CrossRef]

21. Pan, B.; Xing, B.; Liu, W.; Tao, S.; Lin, X.; Zhang, X.; Zhang, Y.; Xiao, Y.; Dai, H.; Yuan, H. Distribution of sorbed phenanthrene and pyrene in different humic fractions of soils and importance of humin. Environ. Pollut. 2006, 143, 24-33. [CrossRef] [PubMed]

22. Hung, W.-N.; Lin, T.-F.; Chiu, C.-H.; Chiou, C.T. On the use of a freeze-dried versus an air-dried soil humic acid as a surrogate of soil organic matter for contaminant sorption. Environ. Pollut. 2012, 160, 125-129. [CrossRef] [PubMed]

23. Laor, Y.; Rebhun, M. Evidence for nonlinear binding of PAHs to dissolved humic acids. Environ. Sci. Technol. 2002, 36, 955-961. [CrossRef] [PubMed]

24. Holbrook, R.D.; Breidenich, J.; DeRose, P.C. Impact of reclaimed water on select organic matter properties of a receiving stream fluorescence and perylene sorption behavior. Environ. Sci. Technol. 2005, 39, 6453-6460. [CrossRef]

25. Chin, Y.-P.; Aiken, G.R.; Danielsen, K.M. Binding of pyrene to aquatic and commercial humic substances: The role of molecular weight and aromaticity. Environ. Sci. Technol. 1997, 31, 1630-1635. [CrossRef]

26. Pan, B.; Ghosh, S.; Xing, B. Nonideal binding between dissolved humic acids and polyaromatic hydrocarbons. Environ. Sci. Technol. 2007, 41, 6472-6478. [CrossRef]

27. Yeh, Y.-L.; Yeh, K.-J.; Hsu, L.-F.; Yu, W.-C.; Lee, M.-H.; Chen, T.-C. Use of fluorescence quenching method to measure sorption constants of phenolic xenoestrogens onto humic fractions from sediment. J. Hazard. Mater. 2014, 277, 27-33. [CrossRef]

28. Wu, J.; Zhang, H.; Shao, L.-M.; He, P.-J. Fluorescent characteristics and metal binding properties of individual molecular weight fractions in municipal solid waste leachate. Environ. Pollut. 2012, 162, 63-71. [CrossRef]

29. McPhedran, K.N.; Seth, R.; Drouillard, K.G. Investigation of Hydrophobic Organic Carbon (HOC) partitioning to $1 \mathrm{kDa}$ fractionated municipal wastewater colloids. Environ. Sci. Technol. 2013, 47, 2548-2553. [CrossRef]

30. Chen, G.; Lin, C.; Chen, L.; Yang, H. Effect of size-fractionation dissolved organic matter on the mobility of prometryne in soil. Chemosphere 2010, 79, 1046-1055. [CrossRef]

31. Wu, J.-Z.; Sun, H.-W.; Wang, C.-P.; Li, Y.-H. Binding of pyrene to different molecular weight fractions of dissolved organic matter: Effects of chemical composition and steric conformation. Chem. Res. Chin. Univ. 2012, 28, 624-630.

32. Xu, H.; Zou, L.; Guan, D.; Li, W.; Jiang, H. Molecular weight-dependent spectral and metal binding properties of sediment dissolved organic matter from different origins. Sci. Total Environ. 2019, 665, 828-835. [CrossRef] [PubMed]

33. Pan, B.; Xing, B.; Liu, W.; Xing, G.; Tao, S. Investigating interactions of phenanthrene with dissolved organic matter: Limitations of Stern-Volmer plot. Chemosphere 2007, 69, 1555-1562. [CrossRef] [PubMed]

34. Yi, M.; Fengchang, W.; Liying, W.; Yingchen, B.; Wen, L.; Haiqing, L. Binding characteristics of perylene, phenanthrene and anthracene to different DOM fractions from lake water. J. Environ. Sci. 2009, 21, 414-423. 
35. Backhus, D.A.; Golini, C.; Castellanos, E. Evaluation of fluorescence quenching for assessing the importance of interactions between nonpolar organic pollutants and dissolved organic matter. Environ. Sci. Technol. 2003, 37, 4717-4723. [CrossRef]

36. Chen, W.; Liu, X.-Y.; Yu, H.-Q. Temperature-dependent conformational variation of chromophoric dissolved organic matter and its consequent interaction with phenanthrene. Environ. Pollut. 2017,222, 23-31. [CrossRef]

37. Chen, X.-M.; Zhao, Y.; Ma, Y.-Y.; Zhu, L.-J.; Yang, T.-X.; Wei, Z.-M.; Dong, Y.-L.; Wei, Q.-B. Assessing the environmental impact of phenanthrene in different types of land use based on the binding characteristics with dissolved organic matter. Ecotoxicol. Environ. Saf. 2018, 147, 394-400. [CrossRef]

38. Lapworth, D.J.; Kinniburgh, D. An R script for visualising and analysing fluorescence excitation-emission matrices (EEMs). Comput. Geosci. 2009, 35, 2160-2163. [CrossRef]

39. Fei, Y.-H.; Li, X.-D.; Li, X.-Y. Organic diagenesis in sediment and its impact on the adsorption of bisphenol A and nonylphenol onto marine sediment. Mar. Pollut. Bull. 2011, 63, 578-582. [CrossRef]

40. Burdige, D.J.; Komada, T. Sediment pore waters. In Biogeochemistry of Marine Dissolved Organic Matter; Elsevier: Amsterdam, The Netherlands, 2015; pp. 535-577.

41. Batchelli, S.; Muller, F.L.; Baalousha, M.; Lead, J.R. Size fractionation and optical properties of colloids in an organic-rich estuary (Thurso, UK). Mar. Chem. 2009, 113, 227-237. [CrossRef]

42. Maizel, A.C.; Remucal, C.K. Molecular composition and photochemical reactivity of size-fractionated dissolved organic matter. Environ. Sci. Technol. 2017, 51, 2113-2123. [CrossRef] [PubMed]

43. Wu, F.; Tanoue, E. Molecular mass distribution and fluorescence characteristics of dissolved organic ligands for copper (II) in Lake Biwa, Japan. Org. Geochem. 2001, 32, 11-20. [CrossRef]

44. Xu, H.; Houghton, E.M.; Houghton, C.J.; Guo, L. Variations in size and composition of colloidal organic matter in a negative freshwater estuary. Sci. Total Environ. 2018, 615, 931-941. [CrossRef] [PubMed]

45. Xu, H.; Guo, L. Molecular size-dependent abundance and composition of dissolved organic matter in river, lake and sea waters. Water Res. 2017, 117, 115-126. [CrossRef]

46. Chen, M.; Hur, J. Pre-treatments, characteristics, and biogeochemical dynamics of dissolved organic matter in sediments: A review. Water Res. 2015, 79, 10-25. [CrossRef]

47. Luo, X.-J.; Mai, B.-X.; Yang, Q.-S.; Chen, S.-J.; Zeng, E.Y. Distribution and partition of polycyclic aromatic hydrocarbon in surface water of the Pearl River Estuary, South China. Environ. Monit. Assess. 2008, 145, 427-436. [CrossRef]

48. Fu, H.; Wei, C.; Qu, X.; Li, H.; Zhu, D. Strong binding of apolar hydrophobic organic contaminants by dissolved black carbon released from biochar: A mechanism of pseudomicelle partition and environmental implications. Environ. Pollut. 2018, 232, 402-410. [CrossRef]

49. Mott, H.V. Association of hydrophobic organic contaminants with soluble organic matter: Evaluation of the database of Kdoc values. Adv. Environ. Res. 2002, 6, 577-593. [CrossRef]

50. Kalmykova, Y.; Björklund, K.; Strömvall, A.-M.; Blom, L. Partitioning of polycyclic aromatic hydrocarbons, alkylphenols, bisphenol A and phthalates in landfill leachates and stormwater. Water Res. 2013, 47, 1317-1328. [CrossRef]

51. Liu, R.; Wilding, A.; Hibberd, A.; Zhou, J.L. Partition of endocrine-disrupting chemicals between colloids and dissolved phase as determined by cross-flow ultrafiltration. Environ. Sci. Technol. 2005, 39, 2753-2761. [CrossRef]

52. Yamamoto, H.; Liljestrand, H.M.; Shimizu, Y.; Morita, M. Effects of physical-chemical characteristics on the sorption of selected endocrine disruptors by dissolved organic matter surrogates. Environ. Sci. Technol. 2003, 37, 2646-2657. [CrossRef] [PubMed]

(C) 2019 by the authors. Licensee MDPI, Basel, Switzerland. This article is an open access article distributed under the terms and conditions of the Creative Commons Attribution (CC BY) license (http://creativecommons.org/licenses/by/4.0/). 